\title{
Long-term outcomes of destructive seronegative (rheumatoid) arthritis - description of four clinical cases
}

\author{
Elena Nikiphorou', Christopher Sjöwall², Pekka Hannonen ${ }^{1}$, Tuomas Rannio ${ }^{1}$ and Tuulikki Sokka ${ }^{1,3^{*}}$
}

\begin{abstract}
Background: Seronegative rheumatoid arthritis is associated with a milder course of progression compared to seropositive disease. However, long-term follow-up data of the clinical course of seronegative rheumatoid arthritis are sparse. Here we describe four cases with a rare disease entity of aggressive destructive seronegative (rheumatoid) arthritis with 20-35 years of follow-up.

Case presentation: The four cases are women with an initial presentation of seronegative rheumatoid arthritis in 1980-1996 and have received disease-modifying anti-rheumatic drugs since the diagnosis. In all cases, the condition has been refractory to treatments and evolved into a severe disease with destructions of the wrists, sub-talar and ankle joints, as well as large joints but not small joints of fingers and toes. All cases are negative with regard to rheumatoid factor, anti-cyclic citrullinated peptide antibodies and antibodies against carbamylated proteins.

Conclusions: This report adds to the existing literature, making the reader aware of this sub-type of inflammatory arthritis which despite being seronegative, can have devastating disease consequences. The report highlights the need for further research into this field in order to better understand this disease sub-type, the pathogenesis, disease course and outcomes.
\end{abstract}

Keywords: Rheumatoid arthritis, Seronegative, Erosions, Outcomes

\section{Background}

Classification criteria for rheumatoid arthritis (RA) have evolved over the decades. Positive serology receives special emphasis in the current criteria [1]. In addition to rheumatoid factor (RF) and anti-cyclic citrullinated peptide (aCCP) antibodies, other RArelated antibodies have recently been identified. These include antibodies against carbamylated proteins (aCarP) [2] and malonaldehyde-acetaldehyde [3], albeit none of these are currently included in classification criteria or used in routine clinical practice.

Autoantibodies are believed to have a pathogenetic role in RA [4]. In studies examining predictors,

\footnotetext{
* Correspondence: tuulikki.sokka-isler@ksshp.fi

${ }^{1}$ Rheumatology/Medicine, Jyväskylä Central Hospital, Keskussairaalantie 19,

Fl-40620 Jyväskylä, Finland

${ }^{3}$ Faculty of Health Sciences, University of Eastern Finland, Jyväskylä Central

Hospital, Keskussairaalantie 19, 40620 Jyväskylä, Finland

Full list of author information is available at the end of the article
}

associating factors, or prevention of RA, seropositive and seronegative groups of patients seem to behave differently [5-7]. In treatment recommendations for RA, seropositivity is recognized as an indicator of severe disease and in these patients, the thresholds for earlier and more intensive/potent disease-modifying treatment are lower [8]. It has become increasingly apparent that our knowledge concerning the pathogenesis, treatment responses and clinical course of seronegative RA, is limited $[9,10]$.

Up to 20-30 \% of patients recruited into RA cohorts and clinical trials are seronegative [11, 12]. An exception is the Finnish Heinola Rheumatism Foundation Hospital early RA cohort from the middle 1970's, which included long-term (25 years) follow-up of seropositive patients only, as experienced rheumatologists were convinced that seropositive disease (positive RF alone at that time) is the only true presentation of 
the disease [13]. This formed the basis of our interest in observing the clinical presentation of seronegative RA.

Observations in our early RA cohorts indicate that long-term radiographic outcomes are different between seropositive and seronegative patients [14]. The natural course of seropositive disease is that of progressive erosions [15], while even in the long- term (e.g. over 20 years), seronegative patients do not present with marked erosions [16]. However, among >3000 patients included in the Jyvaskyla Central Hospital clinical RA database since the 1990's we identified a few consistently RF and aCCP negative individuals with a particular presentation of aggressive, destructive disease. Four cases are presented in detail herein.
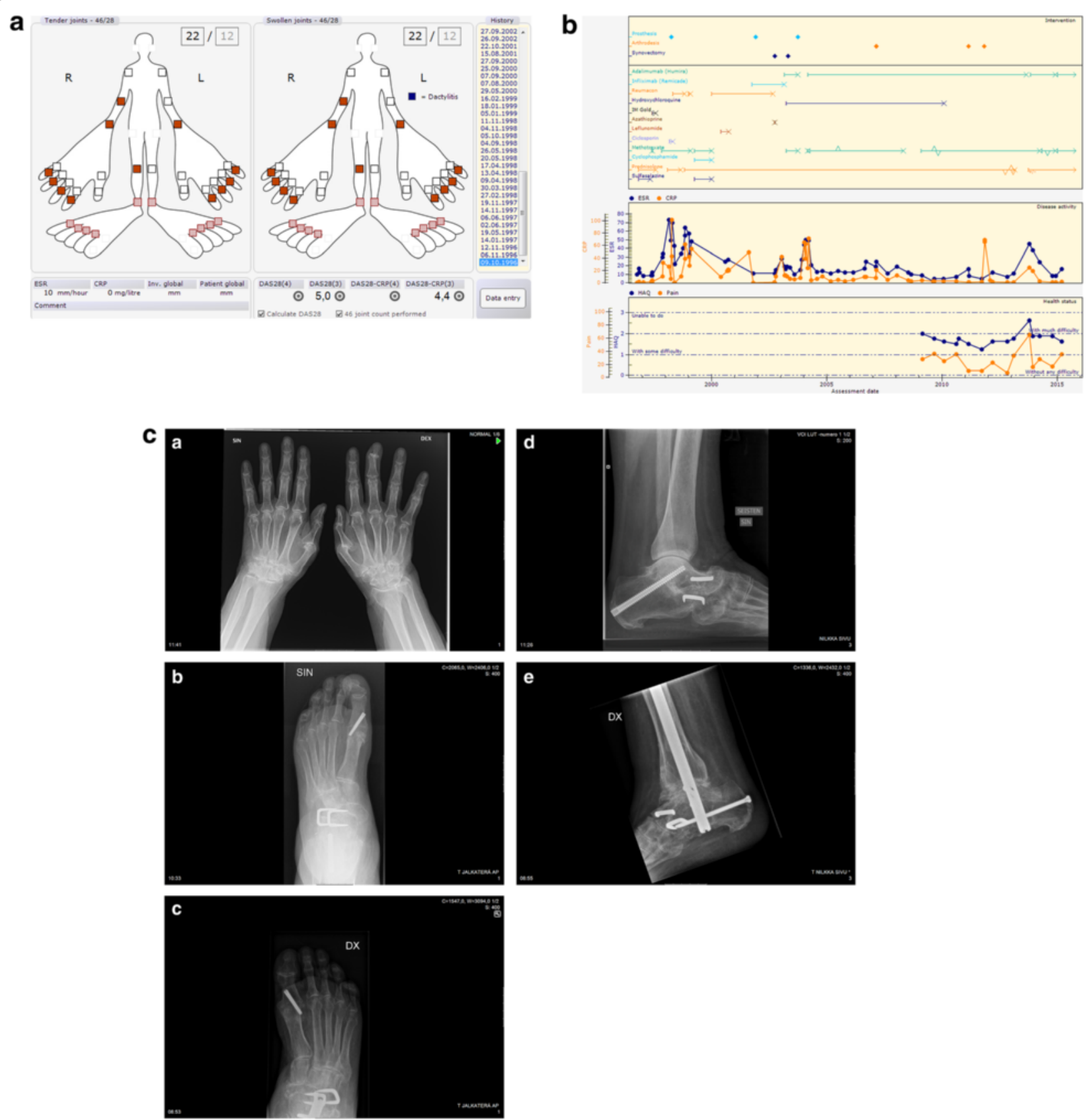

Fig. 1 a Initial clinical presentation of Patient 1. b Progress of Patient 1. c 1-5. Most recent radiographs of Patient 1 (16-19 years from diagnosis) 


\section{Case presentation \\ Case 1}

Demographics: 68 year old female, diagnosed at the age of 50 in 10.1996. Shopkeeper, work disabled since the diagnosis; former smoker.

Initial presentation: Swelling and tenderness starting in the right knee in 01.1996. Intra-articular glucocorticoid injections administered into the right knee four times, until arthroscopy in 08.1996 with macroand microscopic finding of synovitis. Joint symptoms gradually evolved resulting in the diagnosis of clinical polyarthritis in 10.1996. See Fig. 1a.

Comorbidities and Joint surgery: See Table 1.

Medications: Current medications, see Table 1. Previous synthetic and biologic disease modifying anti rheumatic drug (DMARD) treatments were (in order of use): sulfasalazine, gold intra muscular (IM), podofyllotoxin (Reumacon), ciclosporin, cyclosphosphamide, leflunomide, infliximab, azathioprine, and hydroxychloroquine, see Fig. 1b.

Progress: See Fig. 1b. Most recent values for patient reported outcomes and disease activity: HAQ 1.63, pain 35, fatigue 6, patient global 30, ESR 16, CRP 2, DAS28 3.4 indicating moderate disease activity.

Radiographic features: Radiographs on presentation showed no joint damage. The most recent radiographs of hands, wrists, feet, and ankles, taken 16-19 years after diagnosis, are shown in Fig. 1c. Prominent features include joint space narrowing and subluxation of bones in left wrist and meta carpo phalangeal MCP joints, destruction and operation of subtalar, talonavicular and naviculo-cuneiforme joints, as well as right ankle. Typical erosions, seen as in seropositive RA patients are missing.

\section{Case 2}

Demographics: 39 year old female, diagnosed at the age of 16 in 07.1992. Working as a civil engineer. Never smoked.

Initial presentation: The patient sustained a left knee strain while running in 3.1992; symptoms spontaneously resolved within 3 weeks. She was noted to have hyperextension of the left knee in 6.1992 with 7.1992 with synovial fluid aspiration showing 14.000 leucocytes (98\% granulocytes) and a clinical presentation of polyarthritis as shown in Fig. 2a.

Comorbidities and Joint surgery: See Table 2.

Medications. Current medications see Table 2. Previous DMARD treatments included (in order of use): i.m. gold, sulphasalazine, podofyllotoxin (Reumacon), hydroxychloroquine, infliximab, and rituximab see Fig. 2b.

Progress: See Fig. 2b. Most recent values for patient reported outcomes and disease activity: HAQ 0.13,
Table 1 Medical history of Patient 1

\begin{tabular}{|c|c|}
\hline Data extracted & 25.08 .2015 \\
\hline ID & Case 1 \\
\hline Age, Gender & 68 , Female \\
\hline Work status & Pensioner since diagnosis \\
\hline Diagnosis & Rheumatoid Arthritis \\
\hline \multirow[t]{2}{*}{ Diagnosis criteria } & - Symptoms: 1.1996 \\
\hline & - Clinical diagnosis of RA: 10.1996 \\
\hline Highest RF (lgM) & Negative (9) 3.2012 \\
\hline Highest (aCCP) & Negative (4) 8.2009 \\
\hline aCarP & Negative 7.2015 \\
\hline HLA-B27 & Positive \\
\hline \multirow[t]{6}{*}{ Drug (now) } & Methotrexate 1.2015 \\
\hline & - 7,50 mg Subcutaneous Once a week \\
\hline & Adalimumab (Humira) 1.2015 \\
\hline & - 40,00 mg Subcutaneous Every 2. week \\
\hline & Prednisolone 10.2013 \\
\hline & - 5,00 mg Peroral Every day \\
\hline \multirow[t]{9}{*}{ Comorbidity } & Vertebral fracture 10.2005 \\
\hline & Herpes zoster infection 9.2002 \\
\hline & Arm fracture, not wrist 8.2001 \\
\hline & Osteopenia by DXA 2001 \\
\hline & Cholelithiasis 3.1998 \\
\hline & Arterial hypertension 11.1996 \\
\hline & Fibromyalgia 7.1990 \\
\hline & Lumbago/dorsalgia/sciatica 1980 \\
\hline & Migraine - Before rheuma diagnosis \\
\hline \multirow[t]{10}{*}{ Surgery } & Left ankle Arthrodesis 11.2011 \\
\hline & Right ankle Arthrodesis 3.2011 \\
\hline & Left MTP Arthrodesis 3.2007 \\
\hline & Right MTP Arthrodesis 3.2007 \\
\hline & Left knee Arthroplasty 10.2003 \\
\hline & Left knee Synovectomy 5.2003 \\
\hline & Right knee Arthroscopy and Synovectomy 10.2002 \\
\hline & Right knee Rearthroplasty 12.2001 \\
\hline & Right knee Arthroplasty 4.1998 \\
\hline & Right knee Other surgery 8.1996 \\
\hline
\end{tabular}

pain 8, fatigue 12, patient global 9, ESR 2, CRP 5, DAS28 2.1 indicating remission.

Radiographic features: Initial joint radiographs on presentation showed no damage. The most recent radiographs 20-23 years after diagnosis are presented in Fig. 2c. The prominent features are damage in wrists, subluxation of right MCP II, damage of talonavicular and naviculo-cuneiform joints, but minimal erosive changes characteristic of seropositive RA. 


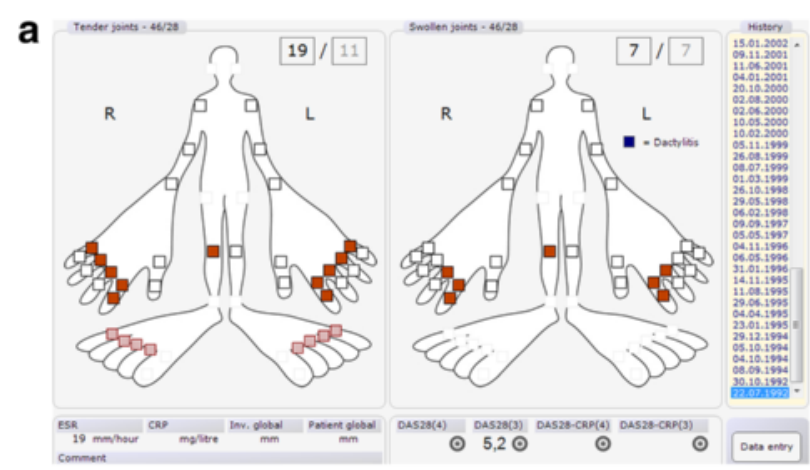

b
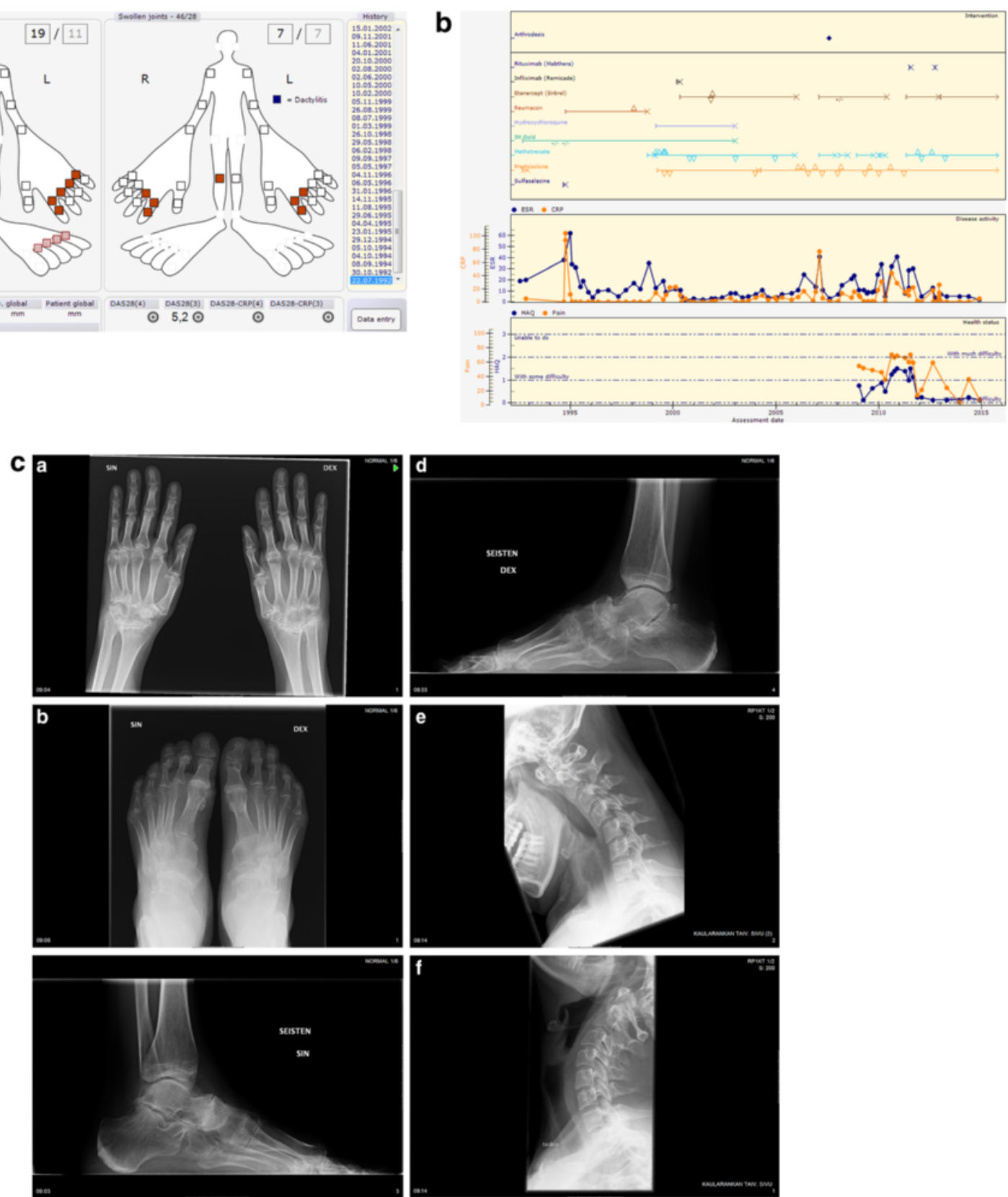

Fig. 2 a Initial clinical presentation of Patient 2. b Progress of Patient 2. c 1-6. Most recent radiographs of Patient 2 (20-23 years from diagnosis; neck radiographs in 2007)

Radiographs of the neck in 2007 indicated a sliding atlanto axial subluxation of $7 \mathrm{~mm}$ in head bending forward -position. An MRI of the neck showed no active pannus and no erosions in the dens.

\section{Case 3}

Demographics: 63 year old female, diagnosed at the age of 28 in 05.1980. Cashier, work disabled since September 1989. Never smoked.
Initial presentation: Temporary pains and aches in knees, wrists, and fingers since the age of 15, and increasing several months prior to the diagnosis in 05.1980 when she presented with a polyarthritis as shown in Fig. 3a.

Comorbidities and Joint surgery: See Table 3.

Medications. Current medications are presented in Table 3. Previous DMARD treatments were (in order): gold i.m., sulphasalazine, auranofin, hydroxychloroquine, 
Table 2 Medical history of Patient 2

\begin{tabular}{ll}
\hline Data extracted & 15.09 .2015 \\
ID & Case 2 \\
\hline Age, Gender & 39, Female \\
Work status & Full-time work \\
Diagnosis & Rheumatoid Arthritis \\
Diagnosis criteria & - Symptoms: 3.1992 \\
& - Clinical diagnosis of RA: 7.1992 \\
Highest RF (IgM) & Negative (8) 2.2012 \\
Highest (aCCP) & Negative (0) 2.2012 \\
aCarP & Negative 7.2015 \\
HLA-B27 & Negative \\
Drug (now) & Etanercept (Enbrel) 1.2013 \\
& $-50,00$ mg Subcutaneous Once a week \\
& Methotrexate 5.2011 \\
& $-15,00$ mg Subcutaneous Once a week \\
& Prednisolone 4.2004 \\
Surgery & $-5,00$ mg Peroral Every day \\
& Neutropenia 12.2012 - 12.2012 \\
& Viral infection 12.2012 \\
& Osteopenia by bone density by DXA 3.2012 \\
& Neck Arthrodesis 8.2007 \\
& Right wrist Tenosynovectomy 10.1995 \\
Comorbidity &
\end{tabular}

D-penicillamine, azathioprine, podofyllotoxin (Reumacon), ciclosporin, cyclophosphamide, chlorambucil, leflunomide, and infliximab (Remicade) see Fig. 3b.

Progress: See Fig. 3b. Most recent values for patient reported outcomes and disease activity: HAQ 1.38, pain 0, fatigue 0, patient global 0, ESR 33, CRP 10, DAS28 3.0 indicating low disease activity.

Radiographic features: No radiographic joint damage was seen at initial presentation. The most recent radiographs 32-35 years after diagnosis are presented in Fig. 3c and show prominent damage in the, wrists, ankle/subtalar/upper forefeet areas, as well as status post orthopaedic surgery in many joints.

\section{Case 4}

Demographics: 60 year old female. Diagnosed at the age of 28 in 12.1982. Waitress, work disabled since 1995, former smoker.

Initial presentation: Symptoms started two years before diagnosis, with synovitis in both knees. Two months prior to diagnosis, symptoms began in other joints with clinical polyarthritis in 12.1982 as presented in Fig. 4a.
Comorbidities and Joint surgery: See Table 4.

Treatment: Current medications are presented in Table 4. Previous DMARD treatments were (in order): Im gold, sulfasalazine, cyclosporine, infliximab, and adalimumab, see Fig. 4b.

Progress: See Fig. 4b. Most recent values for patient reported outcomes and disease activity: HAQ 1.75, pain 59, fatigue 40, patient global 50, ESR 22, CRP 5, DAS28 2.9 indication low disease activity.

Radiographic features: The most recent radiographs of hands, wrists, feet, and ankles, 30-33 years after diagnosis, are presented in Fig. 4c. Destruction of wrists and ankle/subtalar area are prominent, with minimal/no erosions typical for seropositive RA.

\section{Discussion}

These cases all share a common feature: that of a severe, destructive disease in seronegative RA with involvement primarily of the wrists, sub-talar and ankle joints, as well as large joints. All these patients were negative with regard to RF, aCCP, and aCarP. Two cases were HLA-B27 positive but despite this, the clinical presentation (signs and symptoms) and radiographs of the sacro-iliac joints did not support a diagnosis of ankylosing spondylitis (AS) or other spondyloarthritides in these individuals.

Seronegative RA has been in focus of only a few cohorts and rarely in detail, to reveal various aspects of outcomes [9]. Again, an exception is from the Heinola group, which reported long-term outcomes of non-specific seronegative oligoarthritis in patients with a 23 year follow-up [16]. Based on patient history, radiographs and clinical status at the followup visit, they re-classified the 64 patients and found one case each of RA, systemic lupus erythematosus and ankylosing spondylitis, two cases of post-traumatic arthritis, four cases of osteoarthritis, and six cases of possible reactive arthritis. Of the remaining 49 patients, 15 were HLA-B27 positive and 16 had at least one of the psoriasis-related HLA antigens. Seven patients had minor erosions in their hands or feet joints. One HLA-B27 positive patient had developed bilateral sacroilitis by the evaluation at 23 years. Functional capacity of the patients was well retained. Compared to this Heinola seronegative cohort, our patients present a more severe destructive disease, and to date, remain unclassified.

To our experience, patients with destructive seronegative (RF, aCCP negative) RA - as this disease entity can be referred to - are rare. Among our approximately $3000 \mathrm{RA}$ patients, of whom $30 \%$ are seronegative, only a few seem to present with such degree of destructive disease. However, over the years 


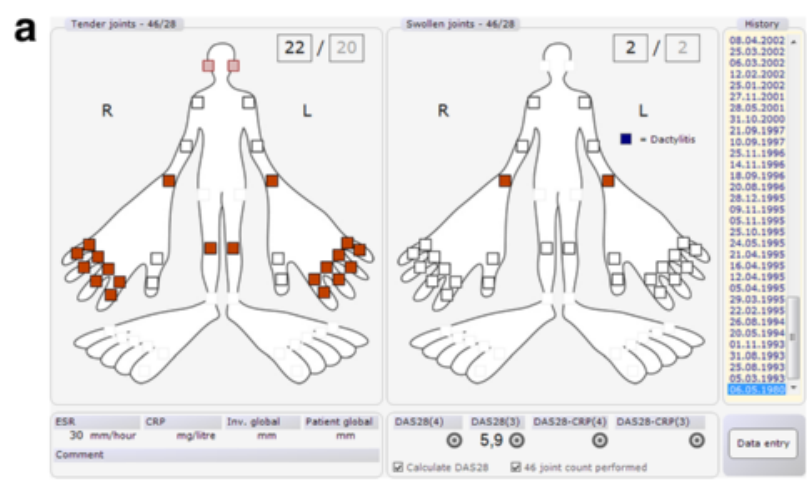

b
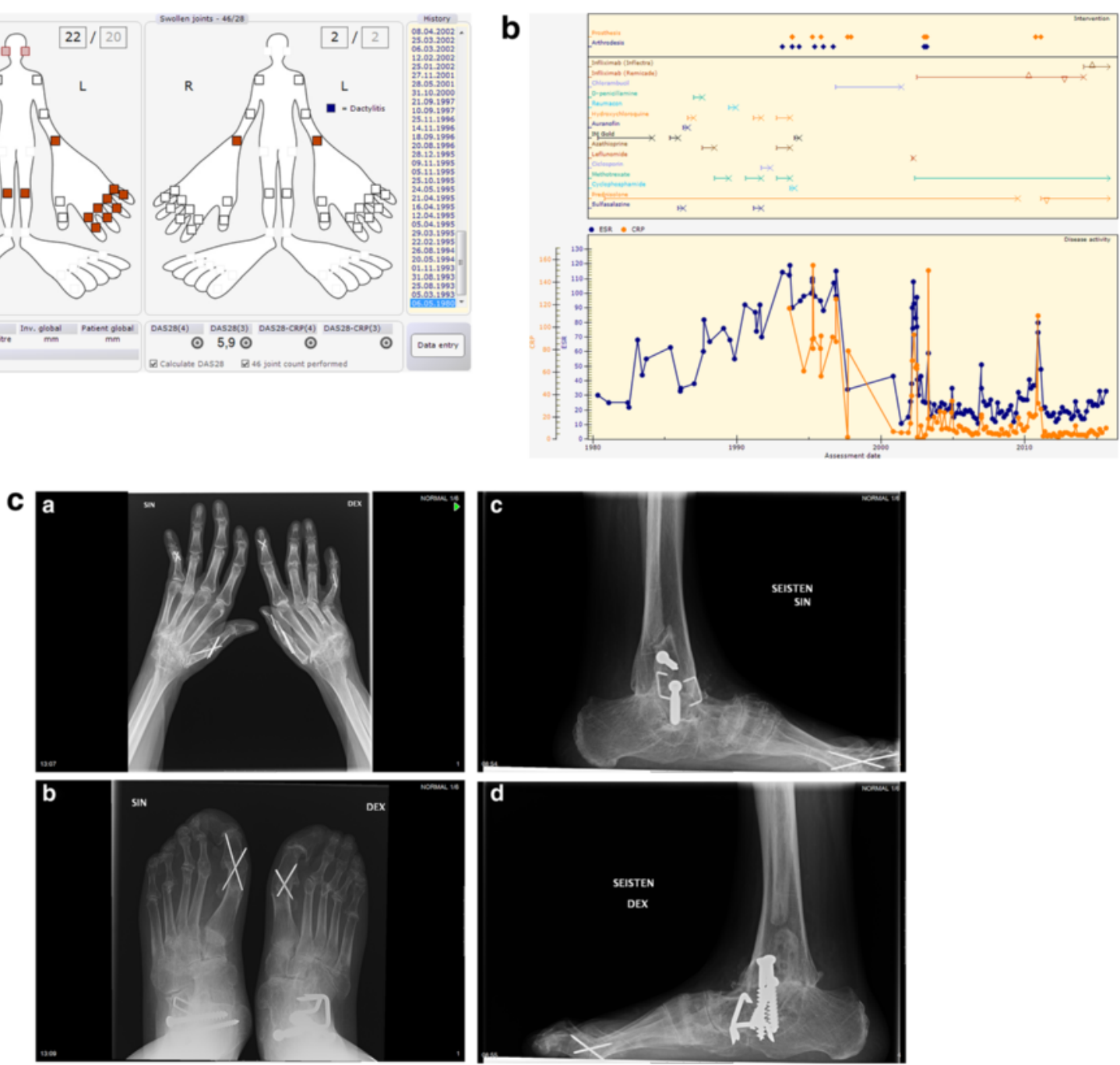

Fig. 3 a Initial clinical presentation of Patient 3. b Progress of Patient 3. c 1-4. Most recent radiographs of Patient 3 (32-35 years from diagnosis)

it is possible that similar cases have been missed, as prior to the era of aCCP analyses, a proportion of RF negative cases demonstrated a typical RF positive course and were later revealed to be aCCP positive. Although destructive seronegative RA is rare, it can have devastating consequences and early recognition and intensive treatment is paramount.

The current clinical status of the patients presented in this report indicates considerable functional loss with a HAQ $>1.5$ in three of the four patients. Despite this, disease activity appears to be under at least some degree of control with DAS28 values between 2.1 to 3.4. Current treatment in all four patients includes prednisolone, methotrexate and biologic agents (combination of two biologic agents in Case 4).
The radiological progression of joint damage in these patients presents major cartilage destruction and loss and with minor bony erosions of joints. In fact, it could even be argued that the radiographic destruction seen in these cases resembles that of advanced seronegative juvenile polyarthritis.

\section{Conclusions}

Through a detailed description of four destructive seronegative (for RF, aCCP and aCarP) RA cases from disease-onset and up to 35 years from diagnosis, this report could shed more light on the disease presentation, course and outcomes of such patients. We hope to inform the reader of this particular subtype of inflammatory arthritis which can result in 
Table 3 Medical history of Patient 3

\begin{tabular}{|c|c|}
\hline Data extracted & 14.09 .2015 \\
\hline ID & Case 3 \\
\hline Age, Gender & 63, Female \\
\hline Work status & Disabled pensioner since 9.1989 \\
\hline Diagnosis & Rheumatoid Arthritis \\
\hline \multirow[t]{2}{*}{ Diagnosis criteria } & - Symptoms: 6.1979 \\
\hline & - Clinical diagnosis of RA: 5.1980 \\
\hline Highest RF (IgM) & Negative (9) 6.2014 \\
\hline Highest (aCCP) & Negative (0) 9.2014 \\
\hline aCarP & Negative 7.2015 \\
\hline HLA-B27 & Negative \\
\hline \multirow[t]{6}{*}{ Drug (now) } & Infliximab (Inflectra) 2.2014 \\
\hline & - 300,00 mg Intravenous Every 8. week \\
\hline & Prednisolone 2.2011 \\
\hline & - 2,50 mg Peroral Every day \\
\hline & Methotrexate 5.2002 \\
\hline & - 10,00 mg Peroral Once a week \\
\hline \multirow[t]{4}{*}{ Comorbidity } & Hyperlipidemia 4.2011 \\
\hline & Hypothyroidism 4.2011 \\
\hline & Osteoporosis by DXA 11.1997 \\
\hline & Arterial hypertension 6.2011 \\
\hline \multirow[t]{18}{*}{ Surgery } & Left elbow Prosthesis 2.2011 \\
\hline & Right elbow Prosthesis 04.10.2010 \\
\hline & Left MCP-1 Arthrodesis 3.2003 \\
\hline & Left MCP-4 Prosthesis 3.2003 \\
\hline & Left PIP-1 Prosthesis 3.2003 \\
\hline & Left PIP-5 Arthrodesis 3.2003 \\
\hline & Right DIP-2 Arthrodesis 1.2003 \\
\hline & Right MCP-1 Arthrodesis 1.2003 \\
\hline & Right MCP-3 Prosthesis 1.2003 \\
\hline & Right MCP-4 Prosthesis 1.2003 \\
\hline & Right PIP-5 Arthrodesis 1.2003 \\
\hline & Right shoulder Prosthesis 12.1997 \\
\hline & Left shoulder Prosthesis 9.1997 \\
\hline & Right ankle Arthrodesis 9.1996 \\
\hline & Right ankle Arthrodesis 1.1996 \\
\hline & Left hip Prosthesis 11.1995 \\
\hline & Right ankle Arthrodesis 6.1995 \\
\hline & Right hip Prosthesis 4.1995 \\
\hline
\end{tabular}

Table 3 Medical history of Patient 3 (Continued)

Left ankle Arthrodesis 5.1994

Right MCP-3 Prosthesis 11.1993

Right MCP-4 Prosthesis 11.1993

Right MCP-5 Prosthesis 11.1993

Right PIP-1 Arthrodesis 11.1993

Left ankle Arthrodesis 3.1993

Right MTP - Joint resection 1990

Left MTP - Joint resection 1990

Right wrist Tenosynovectomy 2.1981 


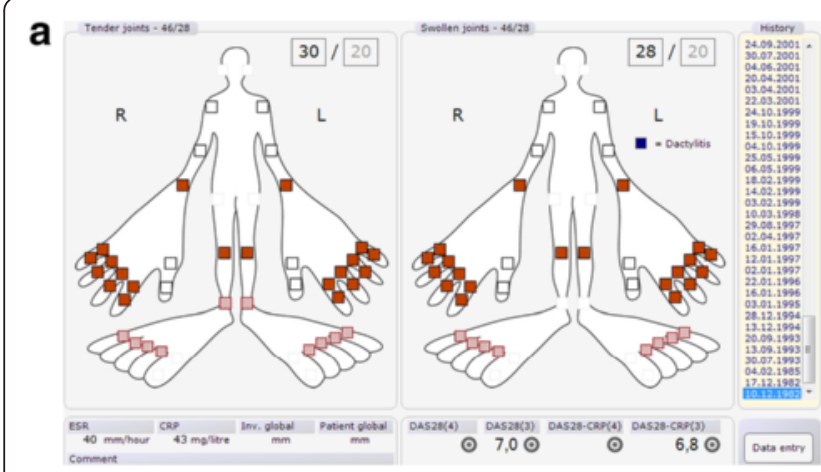

b
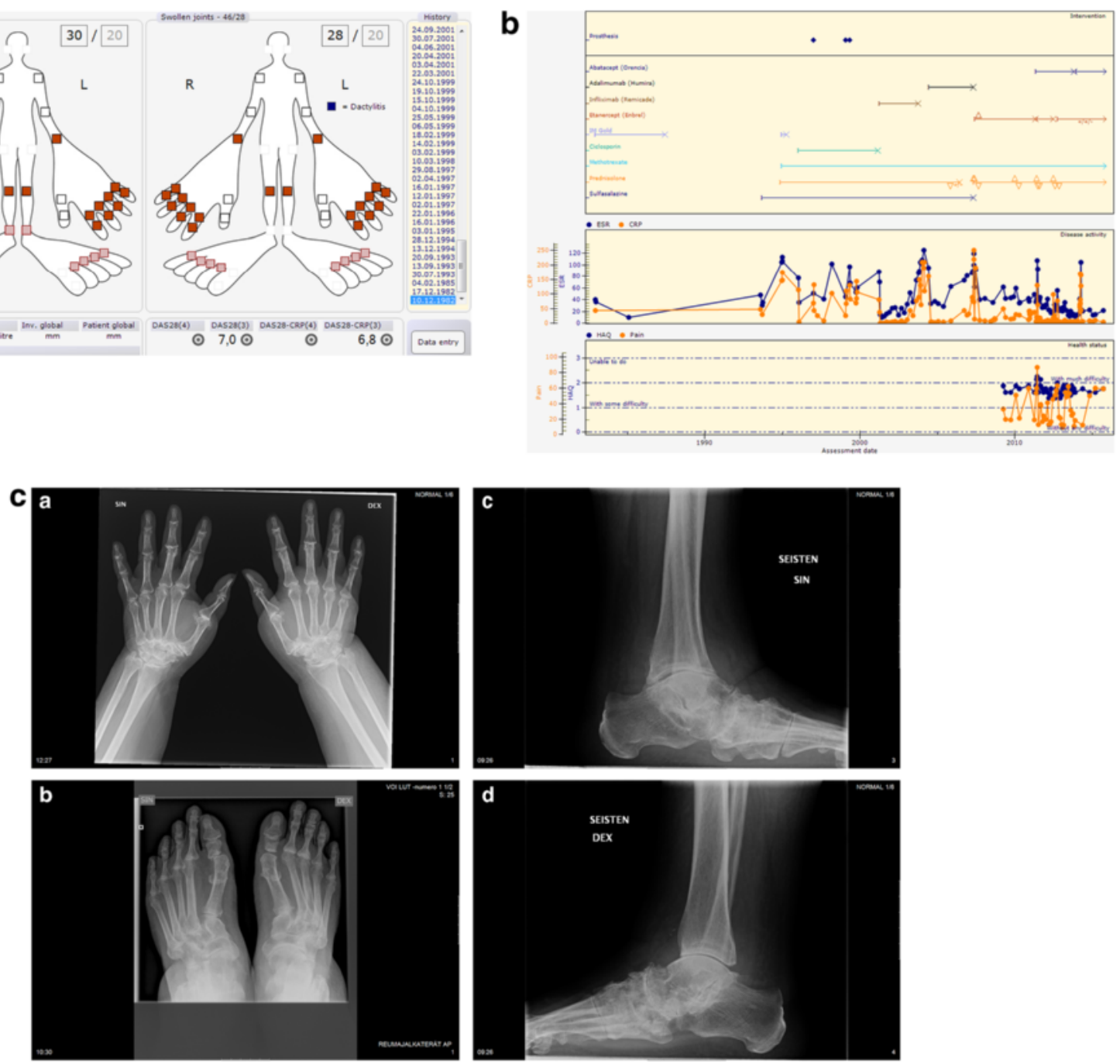

Fig. 4 a Initial presentation of Patient 4. b Progress of Patient 4. c 1-4. Most recent radiographs of Patient 4 (30-33 years from diagnosis) 
Table 4 Medical history of Patient 4

\begin{tabular}{|c|c|}
\hline Data extracted & 14.09.2015 \\
\hline ID & Case 4 \\
\hline Age, Gender & 61, Female \\
\hline Work status & Pensioner since 1995 \\
\hline Diagnosis & Rheumatoid Arthritis \\
\hline \multirow[t]{2}{*}{ Diagnosis criteria } & - Symptoms: 6.1980 \\
\hline & - Clinical diagnosis of RA: 12.1982 \\
\hline Highest RF (IgM) & Negative (8) 4.2009 \\
\hline Highest (aCCP) & Negative (4) 4.2009 \\
\hline aCarP & Negative 7.2015 \\
\hline HLA-B27 & Positive \\
\hline \multirow[t]{8}{*}{ Drug (now) } & Abatacept (Orencia) 12.2013 \\
\hline & - 125,00 mg Subcutaneous Every week \\
\hline & Etanercept (Enbrel) 10.2012 \\
\hline & - 50,00 mg Subcutaneous Every 10. day \\
\hline & Prednisolone 5.2007 \\
\hline & - 5,00 mg Peroral Every day \\
\hline & Methotrexate 12.1994 \\
\hline & - 20,00 mg Peroral Once a week \\
\hline \multirow[t]{9}{*}{ Comorbidity } & Colon diverticulitis 8.2013 \\
\hline & Urinary tract infection 7.2012 \\
\hline & Bacterial infection 6.2012 \\
\hline & Pulmonary embolism 8.2011 \\
\hline & Pulmonary embolism 12.2010 \\
\hline & Asthma 11.2008 \\
\hline & Hyperlipidemia 1.2008 \\
\hline & Arterial hypertension 6.2007 \\
\hline & Osteoporosis by DXA measurement 1.1998 \\
\hline \multirow[t]{3}{*}{ Surgery } & Right hip Prosthesis 5.1999 \\
\hline & Left knee Prosthesis 2.1999 \\
\hline & Left hip Prosthesis 1.1997 \\
\hline
\end{tabular}

devastating patient outcomes and therefore needs prompt identification and treatment, similar to seropositive disease. This report justifies the undertaking of further research on the pathogenesis and identification of possible biomarkers for this type of arthropathy, which could be invaluable in firstly understanding disease behavior and course and secondly in treatment stratification.

\section{Abbreviations}

aCarP, anti-carbamylated protein antibodies; aCCP, anti-cyclic citrullinated peptide antibodies; CRP, C-reactive protein; DAS, disease activity score; DMARD, disease modifying anti rheumatic drug; ESR, erythrocyte sedimentation rate; HLA, human leucocyte antigen; IM/i.m, intra muscular; MCP, meta carpo phalangeal; RA, rheumatoid arthritis; RF, rheumatoid factor.

\section{Acknowledgments}

Dr. Leendert A. Trouw, Leiden University Medical Center, is acknowledged for help with aCarP antibody analyses.

\section{Funding}

EN received a EULAR Scientific Training bursary which supported this work. CS was financed by a grant from the Swedish Society for Medical Research.

\section{Availability of data and materials}

All data concerning the cases are presented in the manuscript or in supplementary material.

\section{Authors' contributions}

Conception and design (TS), acquisition of data (TS, EN, CS), analysis and interpretation of data, drafting the manuscript and revising it critically for important intellectual content, final approval of the version to be submitted (EN, CS, PH, TR, TS). Each author (EN, CS, PH, TR, TS) has participated sufficiently in the work to take public responsibility for appropriate portions of the content; and agreed to be accountable for all aspects of the work in ensuring that questions related to the accuracy or integrity of any part of the work are appropriately investigated and resolved. All authors read and approved the final manuscript.

\section{Competing interests}

The authors declares that they have no competing interests.

\section{Consent for publication}

Consent to publish the data was obtained from the patients.

\section{Ethics approval and consent to participate}

The ethics committee of the Hospital District of Helsinki and Uusimaa provided a positive statements for the study (181/13/03/01/2012) and patients signed informed consent.

\section{Author details \\ ${ }^{1}$ Rheumatology/Medicine, Jyväskylä Central Hospital, Keskussairaalantie 19, FI-40620 Jyväskylä, Finland. ${ }^{2}$ Rheumatology/AIR, Department of Clinical and Experimental Medicine, Linköping University, SE-581 85 Linköping, Sweden. ${ }^{3}$ Faculty of Health Sciences, University of Eastern Finland, Jyväskylä Central Hospital, Keskussairaalantie 19, 40620 Jyväskylä, Finland.}

Received: 16 January 2016 Accepted: 10 May 2016 Published online: 03 June 2016

\section{References}

1. Aletaha D, Neogi T, Silman AJ, Funovits J, Felson DT, Bingham III CO, et al. rheumatoid arthritis classification criteria: an American College of Rheumatology/European League Against Rheumatism collaborative initiative. Ann Rheum Dis. 2010;2010(69):1580-8.

2. Shi J, Knevel R, Suwannalai $P$, van der Linden MP, Janssen GM, van Veelen PA, et al. Autoantibodies recognizing carbamylated proteins are present in sera of patients with rheumatoid arthritis and predict joint damage. Proc Natl Acad Sci USA. 2011:108:17372-7.

3. Thiele GM, Duryee MJ, Anderson DR, Klassen LW, Mohring SM, Young KA, et al. Malondialdehyde-acetaldehyde adducts and anti-malondialdehydeacetaldehyde antibodies in rheumatoid arthritis. Arthritis Rheumatol. 2015;67:645-55.

4. Mclnnes IB, Schett $G$. The pathogenesis of rheumatoid arthritis. N Engl J Med. 2011:365:2205-19.

5. Rantapaa-Dahlqvist S, de Jong BAW, Berglin E, Hallmans G, Wadell G, Stenlund $\mathrm{H}$, et al. Antibodies against cyclic citrullinated peptide and IgA rheumatoid factor predict the development of rheumatoid arthritis. Arthritis Rheum. 2003:48:2741-9.

6. Padyukov L, Silva C, Stolt P, Alfredsson L, Klareskog L. A gene-environment interaction between smoking and shared epitope genes in HLA-DR provides a high risk of seropositive rheumatoid arthritis. Arthritis Rheum. 2004;50:3085-92.

7. van Dongen $H$, van Aken J, Lard LR, Ronday HK, Hulsmans HMJ, Speyer I, et al. Efficacy of methotrexate treatment in patients with probable rheumatoid arthritis: A double-blind, randomized, placebo-controlled trial. Arthritis Rheum. 2007;56:1424-32 
8. Smolen JS, Landewe R, Breedveld FC, Buch M, Burmester G, Dougados M, et al. EULAR recommendations for the management of rheumatoid arthritis with synthetic and biological disease-modifying antirheumatic drugs: 2013 update. Ann Rheum Dis. 2014;73:492-509.

9. Ajeganova S, Huizinga TW. Rheumatoid arthritis: Seronegative and seropositive RA: alike but different? Nat Rev Rheumatol. 2015;11:8-9.

10. Pratt $A G$, Isaacs JD. Seronegative rheumatoid arthritis: pathogenetic and therapeutic aspects. Best Pract Res Clin Rheumatol. 2014;28:651-9.

11. Barra L, Pope JE, Orav JE, Boire G, Haraoui B, Hitchon C, et al. Prognosis of seronegative patients in a large prospective cohort of patients with early inflammatory arthritis. J Rheumatol. 2014:41:2361-9.

12. Sokka T, Kautiainen H, Pincus T, Toloza S, da Rocha Castelar PG, Lazovskis J, et al. Disparities in rheumatoid arthritis disease activity according to gross domestic product in 25 countries in the QUEST-RA database. Ann Rheum Dis. 2009:68:1666-72.

13. Kaarela K. Prognostic factors and diagnostic criteria in early rheumatoid arthritis. Scand J Rheumatol Suppl. 1985;57:1-54.

14. Sokka TM, Kaarela K, Möttönen T, Hannonen PJ. Conventional monotherapy compared to a "sawtooth" treatment strategy in the radiographic procession of rheumatoid arthritis over the first eight years. Clin Exp Rheumatol. 1999;17:527-32.

15. Kaarela K, Kautiainen $\mathrm{H}$. Continuous progression of radiological destruction in seropositive rheumatoid arthritis. J Rheumatol. 1997;24:1285-7.

16. Jantti JK, Kaarela K, Lehtinen KE. Seronegative oligoarthritis: a 23-year follow-up study. Clin Rheumatol. 2002;21:353-6.

\section{Submit your next manuscript to BioMed Central and we will help you at every step:}

- We accept pre-submission inquiries

- Our selector tool helps you to find the most relevant journal

- We provide round the clock customer support

- Convenient online submission

- Thorough peer review

- Inclusion in PubMed and all major indexing services

- Maximum visibility for your research

Submit your manuscript at www.biomedcentral.com/submit 